\title{
Boosting macroevolution: genomic changes triggering qualitative expansions of regulatory potential
}

\author{
Manuel Irimia ${ }^{1,2,3,5,6}$ and Ignacio Maeso ${ }^{4,5,6}$ \\ ${ }^{1}$ Centre for Genomic Regulation (CRG), Barcelona Institute of Science and Technology \\ (BIST), Barcelona, Spain \\ ${ }^{2}$ Universitat Pompeu Fabra (UPF), Barcelona, Spain \\ ${ }^{3}$ Institució Catalana de Recerca i Estudis Avançats, Barcelona, Spain \\ ${ }^{4}$ Centro Andaluz de Biología del Desarrollo (CABD), CSIC-Universidad Pablo de Olavide- \\ Junta de Andalucía, Seville, Spain \\ ${ }^{5}$ Equally contributing authors \\ ${ }^{6}$ Corresponding authors: MI, mirimia@gmail.com; IM, nacho.maeso@gmail.com
}

\begin{abstract}
Two main types of factors have been traditionally considered as potential driving forces underlying macroevolutionary patterns: environmental ('external') cues and genetic and/or developmental ('internal') factors. However, whereas the impact of non-gradual environmental changes has been extensively investigated, the contribution of internal causes, especially of genomic factors, has been approached in a less systematic manner, without clear definitions and classification schemes. Here, taking advantage of recent advances in comparative and functional genomics, we define three types of genomic changes that likely play important roles in macroevolutionary processes: (i) emergence of novel functional genomic properties, (ii) large-scale genome reshaping, and (iii) qualitative single amplifications of regulatory potentials (which we term quasa-regs). Their unifying theme is their ability to qualitatively expand the genomic regulatory potential of the species. We review examples in which these types of changes have likely played important roles and discuss their potential macroevolutionary implications. We conclude that, although such changes may have a minor organismal impact at the time of emergence, they are likely to often have profound long-term effects by expanding regulatory abilities and opening new highways that boost the evolutionary process.
\end{abstract}

\section{Introduction: Macroevolution and genomic change}

Macroevolution traditionally tackles differences between species or larger taxonomic spans. While the distinction between micro- and macro- evolution may be seen as largely quantitative along a continuous axis based on an arbitrary cut-off (the species level), the difference between the two becomes clear at the extremes, e.g. when comparing synapomorphies between two mouse strains or between two phyla (or even mammalian orders). Therefore, one of the main discussions revolts around the extent to which the largescale evolutionary patterns within a macroevolutionary timeframe can be explained by simple accumulation of microevolutionary processes. In other words, whether driving factors of evolutionary change are mostly uniform and constant over time and can thus be extrapolated from microevolutionary events, or if these mechanisms are rather discontinuous 
and dynamic, evolving through time themselves [1]. The lack of uniformitarianism has been investigated from two main perspectives: the genomic changes that give rise to the origin of new variants ("internal factors") and the environmental factors sorting these newly arisen forms in time and space ("external factors").

The importance of sudden and discontinuous environmental changes in shaping the earth biotas is increasingly appreciated, in particular with regards to the impact that mass extinctions has had in macroevolution [2,3]. It is thus widely accepted that the evolutionary pressures and opportunities that result from the interplay between organisms and their environment are highly dynamic in time, leading to punctuated and discontinuous distributional patterns in speciation rates. However, the importance and contribution of key genomic changes to macroevolution has been difficult to tackle. This is to a large extent due to the wide variety of types of genomic changes that have the potential to contribute to macroevolution, particularly in the long term. For instance, an important initial distinction is whether a mutation has a large evolutionary impact due to its molecular or regulatory effects ("genetic factors", in a strict sense; e.g. the origin of a new transcription factor [TF]) or due to a morphological innovation associated to it ("developmental/morphological factors"; see Chapter by Almudi and Pascual-Anaya for examples). Both might fuel subsequent evolutionary events, but their study differs largely at the conceptual and experimental levels. In this Chapter, we explicitly focus on the pure "genetic factors".

Another important distinction concerns the types of processes. At the two extremes, macroevolutionary processes can be broadly split into reductive, by which some lineages become highly streamlined (e.g. certain nematodes, some tunicates, etc.), and constructive, which often increase organismal (usually morphological) complexity. Whereas the latter are the most commonly depicted as macroevolution, the former may be just as common. Moreover, these are just general trends that are not mutually exclusive: highly reduced lineages may still evolve highly complex secondary organs, and, vice versa, more complex groups often reduce or eliminate structures (e.g. limbs in vertebrates). Thus, reductive and constructive only refer to the extremes of a continuum between certain biological contexts that favour more compact, pruned and minimalistic systems versus other contexts that permit more expansive and cumulative processes. Genomic changes leading to (or associated with) reductive macroevolution are well established, particularly with regards to gene loss [4]. However, the genomic factors for constructive macroevolution are much less clear. Most previous proposals concern the so-called Cambrian explosion, the abrupt appearance of a diverse arrange of bilaterian animal phyla in Cambrian deposits. Whether it represents a true burst of morphological disparity or a late coming on the stage of paleontologically concealed lineages that diversified long before, the unmatched diversification of body plans and structures occurred during this period led many researchers to propose that major genomic innovations must have occurred in pre-Cambrian ancestors that fuelled morphological evolution. Examples of these genomic novelties include the emergence of the Hox cluster and associated Hox codes patterning the main body axis ([5], although see recent papers on the presence of Hox codes in cnidarians [6,7]), the origin of CTCF and the evolution of chromatin loops and long-range cis-regulation [8-11] and the hypothesis linking miRNAs repertoires with higher developmental precision and complexity in animals ([12, 13], although this view is highly controversial [14] ). 
One thing that all these suggested genomic changes have in common is their qualitative impact on the regulatory potential of animal genomes. In this Chapter, we build on this idea to propose a global categorization of genomic changes with macroevolutionary potential and discuss the specifics that define and distinguish them from other mutations.

\section{Genomic changes expanding regulatory potential as internal causes for macroevolution}

While any new genomic feature may end up having a long-term macroevolutionary impact, we propose here that most genomic causes for constructive macroevolution must involve changes that qualitatively expand the genomic regulatory potential. By this, we specifically mean that the regulatory abilities that existed prior to the genomic change remain largely unaltered and that new ones are added, thus expanding the regulatory toolbox of the organism (Figure 1). Therefore, the key concepts in the definition are "qualitative" and "expand". First, these types of genomic changes are essentially different to mutations that modify or remodel (not expand) regulatory potentials, e.g. a mutation in a TF that changes its binding specificity. Whereas these normally have dramatic organismal effects (and might in some cases underlie morphological changes), they do not maintain the ancestral regulatory modules and are therefore likely to cause massive pleiotropic deleterious changes. Second, they are also different to, for instance, "classic" creation of cis-regulatory elements that drive expression of a regulator to a new tissue or cell type, since these are, in our view, quantitative, rather than qualitative, expansions of the regulatory potentials (see below for further details).

Although any distinction is certainly arbitrary, we differentiate three categories of genetic factors that qualitatively expand genome regulatory potentials and have likely been associated with constructive macroevolutionary patterns (Figure 1):

A) Novel functional genomic properties. These refer to global features that impact the way genomes encode and decode their regulatory information. They could be considered as new additional axes in the multidimensional space that defines the regulatory potential of a given species (Figure 1). While these properties are widely believed to have a large macroevolutionary importance, it is usually not possible to pinpoint their emergence to specific genomic changes (although see Section 5.3), blurring their association to specific macroevolutionary events. Paradigmatic examples include: long-range transcriptional regulation and 3D genome organization in metazoans, exon skipping-rich transcriptomes in bilaterians and spliceosomal introns in eukaryotes.

B) Large-scale genome reshaping. These can be pinpointed to specific genomic changes, but are "naïve" at the time of the initial mutation and need a cascade of subsequent genomic changes to qualitatively expand the regulatory potential. Paradigmatic examples are whole genome duplications (WGDs) (triggering asymmetric evolution of gene content and gene regulation) and the origin of active transposable elements (TEs) (followed by bursts of transposition).

C) Quasa-regs (Qualitative single amplifications of regulatory potential). These are single genomic changes that instantly expand the genome regulatory potential in a qualitative manner, even if such potential is not immediately realized into organismal or even 
regulatory effects. Paradigmatic examples range from the origin of a new regulator (e.g. a $\mathrm{TF}$, a miRNA, etc.) to interconnections between previously isolated regulatory or biological layers.

We acknowledge that, for most cases, it is impossible to causally associate any of these changes to specific macroevolutionary events (e.g. the origin of new organs or structures); however, a wealth of functional data support that such genomic changes have often been necessary (even if not sufficient) for those evolutionary events to occur. In the following sections, we discuss in detail each of the categories including their paradigmatic examples (Figure 2).

\section{Type A: Novel functional genomic properties}

These are global regulatory properties at the genome-wide scale that are specific to certain lineages and that are believed to have conferred those lineages unique regulatory capacities. By definition, they expand the potential molecular complexity encoded by those genomes and may enable new evolutionary mechanisms for the generation of genomic novelties. However, while this is often associated with increased organismal complexity, it is difficult to demonstrate the direct link (and it is certainly not our purpose here). In this section, we briefly review and discuss three such properties and how they may have contributed to organismal complexity.

3.1) Long-range transcriptional regulation and 3D structure in metazoans. Transcriptional regulation in eukaryotes is mediated by a core promoter at the transcription start site (TSS) and a widely varying number of additional cis-regulatory elements (enhancers, silencers, etc.). These elements can be subdivided into proximal and distal, based on their distance to the TSS. All genes in most eukaryotic species are controlled only by a limited number of proximal regulatory elements. However, in the case of metazoans, the expression of a large fraction of genes is driven by regulatory elements that are far apart from the TSS, distributed across large gene regulatory landscapes (GRLs). As expected, genes with more associated regulatory elements and larger regulatory landscapes have more intricate expression patterns and are usually associated with developmental and regulatory functions $[15,16]$. Therefore, the unique presence of distal transcriptional regulation in animals has been proposed as key for the origin of the exceptionally complex animal body plans and physiologies [17, 18]. Moreover, the relative contribution of distal transcriptional regulation is particularly exacerbated in vertebrates [19], which might in turn be associated with their presumed even larger organismal complexity.

However, while the importance of distal regulation is well known, it is not clear to what extent large GRLs are a cause or a consequence of high organismal complexity, or a mixture of the two. A related important question is whether only animals have distal transcriptional regulation because only they need it to build their body plans or only they can have it, from a mechanistic point of view. Multiple studies suggest that animal regulatory machinery is unique in this regard. Long-range cis-regulatory interactions depend on the formation of chromatin loops associated to the activity of the Cohesin complex and whose borders are usually anchored by dimers of the bilaterian animal-specific protein CTCF [8, 20-23]. In this way, long-range interacting regions that are hundreds of kilobases apart but within the same 
loop are being brought together, while immediately neighbouring genomic loci that belong to different loops can be kept isolated, preventing ectopic gene regulatory interactions [24-26].

Can this unique animal mechanism be pinpointed to specific genomic changes? While most of the proteins that are part of the Cohesin complex are ancestral to all eukaryotes, several architectural proteins with important roles in the formation of chromatin loops and boundaries have not been found in non-animal genomes, suggesting a potential association between the origin of these genes and the emergence of distal regulation. In particular, CTCF is only present in bilaterian animals [8], and Ying Yang1 (YY1), seems to be animalspecific (Alex de Mendoza, personal communication). Interestingly, this situation has been secondarily modified in some lineages [27]. For instance, it seems that CTCF no longer plays a significant role in the establishment of chromatin loops and long-range interactions in Drosophila [28], most probably as a result of the evolution of multiple novel architectural proteins that are insect and fly-specific [29, 30], which could have taken over CTCF ancestral functions. Similarly, in certain nematodes such as Caenorhabditis elegans, CTCF and YY1 have been lost, which seems associated with the dismantling of most of the ancestral long-range regulation in the context of the highly compact, gene-dense genome characteristic of highly derived chromadorean nematodes [8, 31-33]. Intriguingly, with different degrees, these nematodes show secondarily streamlined body plans, which could further support an association between distal regulation and organismal complexity. Finally, although there is cumulative evidence that long-range regulatory interactions are ancestral to all animals [11, 17, 18, 34-37], CTCF is most probably a bilaterian innovation (see Section 5). Therefore, it is currently unclear which were the molecular mechanisms responsible for the establishment of chromatin loops and distal regulation in non-bilaterian lineages such as sponges and cnidarians and in the last common ancestor of metazoans, although the previously mentioned case of Drosophila suggests that CTCF could have replaced a yet unknown ancestral architectural protein(s).

Whatever the mechanisms, and although we still have to be cautious given that only a handful of non-animal lineages have been studied so far, there seem to be clear differences in genome organization between animals and other eukaryotes. In animals, in addition to the ancestral eukaryotic mode of chromatin organization that roughly corresponds to transcriptionally active/inactive compartments, there would be additional players, such as architectural proteins, that could also act as drivers for the establishment of 3D chromatin interactions [21, 28, 38-40]. As a result, animal genomes have distinctive chromatin interaction patterns, which are characterised by the presence of the so called Topological Associating Domains (TADs). Thus, a question emerges within the context of this review: could 3D genomic organization also be a potential genomic factor in macroevolution or is it simply a consequence of complex distal regulatory interactions? At least at the genomic level, the unique animal 3D chromatin architecture is known to affect profoundly how animal genomes are structured and evolve. Distal cis-regulatory elements of developmental regulators can be so far away from their target promoters that they are often located within unrelated neighbouring genes, giving rise to microsyntenic associations that cannot be disrupted without compromising the establishment of essential long-range chromatin loops. Accordingly, not all genomic rearrangements in evolution are equally well tolerated and animal genomes are characterized by the presence of certain "islands" of conserved microsynteny that correspond to the presence of large GRLs or genomic regulatory blocks $[11,16,18,41-43]$. Animal genomes also have gene-dense regions devoid of key 
developmental regulators that show an organizational pattern that would be more similar to the ancestral eukaryotic organization based on transcriptional activity. These gene-dense regions are expected to follow a very different evolutionary route, with little conservation of microsyntenic associations (except those corresponding to pairs of genes sharing a bidirectional promoter [18]). Thus, from the perspective of synteny evolution and genome rearrangements, animal genomes would be composed by regions ranging between two different situations: (i) evolutionary stable, highly conserved regions associated to the large GRLs of developmental regulators, and (ii) gene-dense regions with higher rates of rearrangements. Related to this, a recent study has shown that the evolution of genomic organization in animals would not just be the result of selective constraints against the disruption of long-range cis-regulatory interactions, but that the same molecular mechanisms and structures responsible for the 3D chromatin organization can create hotspots for double strand breaks and genomic rearrangements, in a process involving Topoisomerase II beta (TOPO2B) at CTCF-anchored loop borders [44]. This in turn will create new gene neighbourhood associations that in certain cases could give rise to new long-range regulatory interactions and evolutionary relevant changes in gene expression [45-48]. Therefore, while these "terminal" regulatory changes would not generally qualify as changes that qualitatively expand the regulatory potential (they are changes in cis-regulation that modify these quantitatively), the ability to reorganize the genome based on GRL and TAD structures is a potential Type A factor that qualitatively changes how the genomes (and thus organisms) may evolve. This process bears similarities with exon shuffling, but at the genome rather than the gene level. Here, instead of shuffling exon units thanks to the presence of intervening introns (which are an eukaryotic Type A macroevolutionary factor as well), genomes shuffle GRLs (or parts of GRLs in the case of intra GRL CTCF sites) thanks to the nature of their loops. As such, we may refer to this process as GRL-shuffling or TADshuffling.

3.2) Exon skipping-rich transcriptomes in bilaterians. Alternative splicing (AS) consists in the differential selection of competing splice sites during pre-mRNA processing. Thus, by processing introns and exons in different ways, eukaryotic cells can generate multiple transcripts per gene, quantitatively expanding their transcriptomic complexity. There are several types of AS, among which the most prevalent are exon skipping (the complete inclusion/removal of an exon into/from the final mRNA) and intron retention (lack of removal of an otherwise intronic sequence). Both types of AS have now been reported in all eukaryotic lineages $[49,50]$, placing their origin in the last common ancestor of eukaryotes. However, the frequencies of each type show remarkably different phylogenetic patterns: whereas intron retention is observed at high levels in all eukaryotes, exon skipping is only highly prevalent in bilaterian animals.

What are the potential functional and macroevolutionary consequences of these distinct phylogenetic patterns? AS may exert different effects on gene function, including the generation of alternative protein isoforms and the post-transcriptional downregulation of gene expression. Importantly, whereas the latter is normally associated with intron retention, the former is tightly linked to exon skipping. Dozens of single-case studies have shown that different protein isoforms may have different molecular properties (e.g. subcellular location, half-life, binding affinity) and, in some case, even play antagonistic biological roles (e.g. promote apoptosis vs. cell proliferation, act as dominant negatives, etc.) [51-53]. Moreover, large-scale analyses of protein-protein interactions revealed that a large fraction of exon 
skipping events modulate interactions with specific partners, leading to the rewiring of interaction networks [54-56]. In addition, studies using high-throughput sequencing data have shown that exon programs are coordinated in a cell type- and tissue-specific manner, together impacting multiple cellular pathways [57, 58]. These programs are particularly common in central nervous systems, and knockouts of specific RNA binding protein regulators often have dramatic impacts on embryonic development and function [59-64] . Therefore, given its potential to expand functional proteomic repertoires and that it is found at high levels only in bilaterian animals [49] (and even more so in mammals [65]), exon skipping has long been associated with higher organismal complexity [66,67]. Although this association is certainly impossible to prove at the causal level, it is at least plausible that some macroevolutionary differences between bilaterians and other eukaryotes, as well as within bilaterians, now depend on tightly regulated AS patterns. As such, the large fractions of exon skipping observed in bilaterians and their usage to amplify cellular proteomes [49], qualifies as a novel genomic feature that has qualitatively expand their regulatory potential.

What are the genomic changes underlying the emergence of this global regulatory feature? While mechanisms leading to the origin of new alternative exons are well documented and they are highly dynamic in evolution [68-73], here we do not refer to specific cases, but to the ability to produce and regulate exon skipping-rich transcriptomes. This ability has been largely associated with the mechanism by which exons are recognized in the pre-mRNAs [74]. Traditionally, two major mechanisms are considered: intron definition and exon definition. In intron definition, presumably ancestral, short introns surrounding long exons are defined by the pairing of U1 and U2 snRNPs at the 5' and 3' splice sites of each given intron, respectively. In the case of exon definition, small exons surrounded by long introns are defined first, and the first pairing between snRNPs from the surrounding introns occurs across the exon $[75,76]$. Importantly, errors during intron definition are expected to lead to intron retention, whereas those during exon definition are more likely to result in exon skipping. Assuming that these errors are the raw material for AS evolution, what may have tipped the scales towards more exon definition at the origin of bilaterians? There are two non-mutually exclusive hypotheses: the origin of new proteins that facilitate exon definition and genome-wide changes in exon-intron structures. The first one is difficult to test, since the spliceosomal proteins that are specific for exon definition (if any) are largely unknown. In this context, SR proteins are good candidates, since they normally bind (alternative) exons, generally promoting their inclusion [74]. Consistently, several SR protein families have been expanded during animal evolution [77]. Regarding the modification of intron-exon structures, a genome-wide increase towards exon-defining structures (particularly an increase in intron lengths) has been inferred for the last common ancestor of bilaterians and proposed to have played a major role in the origin of exon skipping-rich transcriptomes [49]. This may have also in turn fuelled the expansion of SR proteins. What has caused this increase in intron lengths? For any given intron, increases in length are likely neutral, and thus may occur globally largely due to mutational biases. However, it is plausible that, at least in some instances, the concomitant presence of distal transcriptional regulation in metazoans may have led to larger introns, particularly in genes with complex GRLs (e.g. [78]). If so, these two novel functional genomic properties (distal transcriptional regulation and exon-skipping rich transcriptomes) may have established a positive feedback loop [49] with the associated regulatory consequences. 
3.3) Hypermethylated genomes in vertebrates and other lineages. Cytosine DNA methylation (5-methylcytosine, $5 \mathrm{mC}$ ) is an ancestral feature of eukaryotic genomes with important regulatory functions and long-term effects on DNA mutation rates and genome evolution. The last common eukaryotic ancestor probably had low to intermediate levels of $5 \mathrm{mC}$ with a "mosaic" distribution targeted to gene bodies (probably to prevent spurious transcriptional initiation) and transposable elements (to silence and control their expansion) $[79,80]$. However, there have been multiple secondary elaborations of this primitive situation, particularly in animals, with $5 \mathrm{mC}$ levels and distribution patterns across the genome varying wildly among different lineages, from zero or very little methylation in Drosophila and $C$. elegans to the globally methylated genomes of vertebrates $[79,80]$. The genomic changes and evolutionary mechanisms that led to these differences are not well understood (setting aside the obvious association between loss of different Dnmt genes and loss of methylation). Nevertheless, it is clear that changes such as the acquisition of high global $5 \mathrm{mC}$ content in vertebrates have profoundly changed the chromatin environment of their genomes, with a potentially strong impact on transcriptional regulation. In fact, in addition to their global methylation, vertebrates show another distinctive feature: their embryonic transcriptional enhancers have a decrease of $5 \mathrm{mC}$ levels when activated during late embryogenesis [81]. However, amphioxus, a non-vertebrate chordate closely related to vertebrates, has been recently shown to have adult-specific enhancers that become demethylated during development, similar to vertebrates [19]. Remarkably, this enhancer demethylation occurs despite the fact that amphioxus $5 \mathrm{mC}$ content is very similar to that in the ancestral eukaryotic condition, with low levels of methylation largely associated with actively transcribed gene bodies [19, 82]. For this reason, amphioxus demethylated enhancers are almost exclusively found within gene bodies of widely expressed genes, suggesting that $5 \mathrm{mC}$-dependent enhancer regulation could have originated to help the identification and activation of enhancers that were located in hypermethylated intragenic contexts. Later on, when methylation levels increased dramatically in the vertebrate lineage, the ancestral enhancer demethylation mechanism could have been co-opted (or simply required) to regulate distal intergenic enhancers, which are particularly abundant in vertebrates (see Sections 3.1 and 4.1). The evolutionary mechanisms and possible causes responsible for this global shift towards a pervasive $5 \mathrm{mC}$ content in vertebrate ancestors are unknown. However, it is tempting to speculate that it was associated with distal transcriptional regulation and the general genome expansion with massive GRLs and intron sizes. In this scenario, genome-wide methylation may have evolved to avoid that undesired distal sequences act as spurious enhancers interfering with transcriptional regulation, which were more likely to occur given the large sizes of GRLs and the presumably more prevalent role of distal regulation in vertebrates. Whatever the case, what is clear is that such a global change in the functional properties of the chromatin posed new and important evolutionary challenges and opportunities that expanded previously existing regulatory mechanisms (enhancer demethylation) to new contexts (intergenic regions and gene deserts). Whether that truly implied an expansion of the regulatory potential or not, still requires further data on the importance of $5 \mathrm{mC}$ in the control of gene expression.

\section{Type B: Large-scale genome reshaping}

From the perspective of the whole genome, the physical scope of most genomic changes can only be considered as local; that is, as circumscribed to just a relatively small and 
regional fraction of the entire "genomic space". However, certain mutational processes do have large-scale pan-genomic effects. As such, this type of global changes could be viewed as genomic "revolutions", with the potential to change the tempo and the mode in which a particular lineage will subsequently evolve. In this section, we discuss two types of largescale changes: WGD- and TE-associated genome reshaping. In both cases, the initial mutation leading to the reshaping is well understood (WGD and the acquisition of an active TE). However, in both cases the final outcome of such mutations is highly variable, although general principles have been inferred from investigating cases of recurrent evolution in several independent lineages [83].

4.1) Whole genome duplications. WGDs (including both autopolyploidies and allopolyploidies) are arguably the most massive genomic change that can be generated in a single evolutionary event. Nevertheless, WGDs are rampant in plants [84-86], where they have been linked to speciation, and a wealth of recently reported cases show that their prevalence in animals may be much higher that traditionally appreciated [87-90]. Importantly, some well characterized WGDs are very old and preceded the diversification of highly diverse and speciose lineages, such the well-studied WGDs ancestral to vertebrates and teleost fish and the recently reported WGD at the origin of arachnopulmonates (scorpions and spiders [90]). This has led to speculations as to whether these ancient WGDs facilitated the evolution of morphological innovations and ecological adaptations in these clades (for instance through the increased regulatory lexicon originated by preferential retention of duplicated 'developmental' gene families and transcription factors [91]). These hypotheses are controversial, mostly because there is currently no evidence in the fossil record of a tight temporal association between the occurrence of known WGD events and an increase of the morphological disparity and species richness of the corresponding animal clade [92-94]. Furthermore, the purported increase in regulatory complexity triggered by WGDs has been difficult to quantify. However, the evolutionary consequences of WGDs do not have to be fully realized immediately after their occurrence. Indeed, gene duplicates and associated regulatory elements are identical immediately after the WGD and thus further regulatory and/or protein-coding changes are needed to drive innovation. This means that WGDs are initially naïve: at early stages, the organisms with a WGD are probably not very different from their closest non-duplicated relatives (but see [95, 96]). Nonetheless, under appropriate circumstances, these species may have better chances to survive and then diversify, as it has been suggested in the case of land plants at the KT mass extinction [97].

How does WGD enable expanded regulatory potentials? Intuitively, the access to an expanded repertoire of genomic elements is likely to result in higher molecular complexity, and this is particularly the case given the well-established bias for retention of multiple copies of regulatory vs. housekeeping genes [91][98]. But, only recently, with the advent of a wide variety of functional genomics tools, we have started understanding the regulatory paths after WGD. For instance, a recent study comparing transcriptomic and chromatin accessibility data from duplicated (vertebrates) and non-duplicated species (amphioxus) reported marked asymmetric regulatory evolution of members of gene families that have retained multiple copies in vertebrates [19]. In particular, the most common fate is specialization, whereby at least one copy maintains the ancestral breath of expression, and at least another copy gets its expression restricted. In a large fraction of cases, these copies were restricted to a single tissue (often the brain) and underwent high rates of protein coding sequence change, consistent with neofunctionalization or optimization of their function in the 
specific tissue. Furthermore, genes that have retained multiple copies tend to have larger GRLs with more cis-regulatory elements, although these also occurs asymmetrically among the copies: some have kept similar numbers to the outgroup, but others have undergone dramatic expansions. Strikingly, the specialized copies, and not those expressed broadly, are the ones that have undergone those expansions. In summary, while WGDs may have little organismal impact at the time of the mutation, they pave the way for a major reshaping and expansion of the new genome's regulatory potential.

4.2) Burst of transposable elements: The arrival or creation of a new TE type in a genome, when followed by a rapid and massive genome-wide expansion and colonization, constitutes another prominent example of (relatively) fast large-scale genomic remodelling initiated by a single foundational mutation with little or no immediate regulatory effect. All animal genomes sequenced to date bear signatures of successive waves of invasions of different TE families. The presence of many copies of very similar TE sequences widely distributed across the entire genome can boost genome evolution in many ways, including reshuffling genome organization and syntenic associations [99] and promoting gene family expansions through duplications driven by hotspots of non-homologous recombination [100]. Furthermore, TEs can also be exapted as new protein coding genes [101-105], and, perhaps more importantly, they are probably the main primary source for new cis-regulatory elements [106-108]. In fact, since any given TE family can potentially acquire a genome-wide distribution, TE-derived cis-regulatory elements can be responsible for the de novo assembly and/or rewiring of entire gene regulatory networks (GRNs) [107]. For instance, these evolutionary processes could have been of paramount importance during the evolution of placental mammals, in the transcriptional regulation of early developmental stages and the placenta [109-111]. Moreover, the impact of these processes is likely underappreciated: since the regions of the TEs that are not under evolutionary constraint as well as all TE copies that have not been exapted will diverge beyond recognition relatively quickly, it is usually not possible to identify really ancient (i.e. phylum-wide or older) TE expansions (with some remarkable exceptions [112]). Thus, most probably we will never know if TE invasions contributed in any way to, for instance, an increase in the complexity of gene regulatory networks of early animals [36].

\section{Type C: single genomic changes that qualitative expand regulatory potential (quasa-regs)}

Type B changes can be traced back to an initial mutational event; however, those initial mutations are expected to have had a very limited impact on the regulatory potential of the genome at the time of emergence (even if they had an immediate effect on cellular size or others organismal characteristics in the case of WGDs). It is only after subsequent mutational events when the expansion of the regulatory potential is defined. In this section, we will discuss genomic changes that, due to their specific nature, instantly expand regulatory potentials. In fact, they may have little or no impact on the actual genome regulation (e.g. specific genes being up- or down-regulated) when they arise, but the expansion of the regulatory potential is already defined. Perhaps the simplest example is the origin of a new TF. Even if the network of targets needs to be built and pruned by subsequent mutations, the TF's new regulatory ability and specificity are already available as 
part of the genome's regulatory toolkit (e.g. the ability to regulate genes with a given sequence motif in their promoters). We therefore termed this class of changes "Qualitative single amplifications of regulatory potential", quasa-regs, to emphasize their disruptive nature generating amplifications of regulatory potentials in a single event. We describe here the following arbitrary classes of quasa-regs:

5.1) Origin of new regulatory genes. Most of the literature that has investigated changes in gene repertoires that presumably underlay macroevolutionary events (e.g. the origin of multicellular animals or the Cambrian explosion) has paid particular attention to the emergence of novel regulatory genes, such as TFs and genes involved in signalling pathways and cell-communication systems [36, 113, 114]. Although establishing a causal link between the appearance of a regulatory gene and a macroevolutionary event is not possible in most cases, it is relatively straightforward to show that a given regulatory gene is necessary for the development of the specific macroevolutionary novelty (e.g. the KO of a TF leading to loss of a morphological structure during development), making these arguably the most intuitive types of quasa-regs. These cases include the origin of every family of TFs with important developmental roles in animals and plants [115], but also RNA binding proteins with diverse regulatory functions (in AS, translation, cellular location, etc.) [116]. Often, the key event is the origin of a novel DNA or RNA binding domain with a new binding specificity that expands the species' regulatory lexicon (at the core of our definition of regulatory potential). However, domains with other molecular functions may also be instrumental, such as the recruitment of a transcriptional repressor after gene duplication (e.g. in the case of the diversification of the SoxB1 and SoxB2 TF family $[117,118])$. In addition, the birth of any bona fide non-coding regulatory RNAs (including microRNAs, long non-coding RNAs, etc.) falls in this category.

5.2) Origin of protein isoforms in regulators with new specificities. This type of novelties is related to those described in Section 5.1, but they differ in their molecular mechanism, which may have important regulatory consequences. While the examples described above concern the origin of novel regulatory loci, these cases involve the origin of alternative isoforms, either by AS or other pre- or post-transcriptional mechanisms, within pre-existing regulatory genes. For instance, the TF FOXP1 harbours a mutually exclusive exon skipping event in which either exon 18 or $18 \mathrm{a}$ is included in the final mRNA [119]. These exons encode part of the DNA binding domain of the TF, resulting in proteins with different binding specificities. Interestingly, the isoform including exon 18a (FOXP1-ES) is only expressed in embryonic stem cells and primordial germ cells in mammals, but not in differentiated tissues. Therefore, only in those cells, the FOXP1 TF gene product regulates a specific network of pluripotent-associated genes that have the FOXP1-ES-specific binding motif in their cis-regulatory elements. Similar cases have been described for other TFs, such as Pax6 [120] and Tcf7/2 [121]. A very remarkable case is the alternative inclusion of a 12nucleotide microexon in the histone lysine demethylase $K d m 1 a$. The skipping isoform has $\mathrm{H} 3 \mathrm{~K} 4 \mathrm{me} 1 / 2$ as main substrate. However, inclusion of the microexon changes substrate specificity to H3K9me1/2 [122] and H4K20me1/2 [123]. Given that the microexon is only included in neurons (see Section 5.3.4), the emergence of this isoform presumably expanded the potential for histone modification in the nervous system. Consistently, KO mice for this microexon have dramatic deficits in spatial learning and long-term memory formation [123]. In another striking example, the origin of an exon in the eukaryotic elongation factor 1Bס (EEF1D) in amniotes converts an ancestral translation elongation 
factor into a heat-shock response TF specifically in the brain and testis [124]. The isoform with the new exonic sequence in its $\mathrm{N}$-terminus is located to the nucleus and induces genes with heat-shock elements in their promoters through interaction with various co-factors [124].

It is important to also point out that, while there are many other examples of AS regulating TFs and other regulators, it is worth mentioning that not all these changes fall under our definition of genomic changes that qualitatively expand the regulatory potential. For instance, multiple AS events create inactive protein isoforms (e.g. Rest [125]) or isoforms that have quantitatively different DNA binding affinities (e.g. Pax7 [126]) or trans-activator activities (e.g. [78, 127]). While these may have high regulatory (and evolutionary) importance, in our view, they involve quantitative, not qualitative, changes in the regulatory potential. An interesting case is the evolution in mammals of the skipping of exon 9 in the AS regulator Ptbp1, which is constitutively spliced in other vertebrates [128]. While this exon skipping event confers quantitatively different repressive activities to Ptbp1 protein isoforms and these are dynamically regulated during neuronal differentiation, which has a large impact on the transcriptome [128], in our view the origin of exon 9 skipping in mammals does not qualify as a quasa-reg, as it results from a quantitative modification of the function.

5.3) Origin of novel genes or isoforms that enable new functional genomic properties. Although they may be considered a subtype of the novelties described in sections 5.1 and 5.2, we discuss them individually given their interconnection with functional genomic properties (Type A factors, Section 3). The origin of these regulators can happen through the emergence or recruitment of novel protein domains capable of binding DNA, RNA and/or histones (for instance by domesticating proteins of TE origin) or by shuffling pre-existing domains giving rise to new catalytic functions. Furthermore, it is also possible that novel domains with completely new biochemical functions arise that allows a novel mode of regulation.

5.3.1) Novel architectural proteins (Type $C$ ) and distal transcriptional regulation and complex 3D genome organization (Type A): As mentioned above, the architectural proteins CTCF and $Y Y 1$ are bilaterian and metazoan specific, respectively, and thus their origin may be behind the establishment of distal transcriptional regulation and the complex 3D organization in animal genomes. Although the evolutionary route leading to the emergence of the animaltype long-range regulation is not well understood, it is clear that the presence of proteins that are capable of establishing chromatin loops must have been an important step. Interestingly, such a molecular function may be relatively simple to evolve. Both CTCF and YY1 consist of multiple zinc finger domains that bind DNA and are able to dimerize, bringing the two regions of bound DNA together to form a loop. Thus, this system is likely to evolve repeatedly, as attested by the replacement of CTCF by other structural proteins in flies [29, 30]. However, the origin of the molecular system is unlikely to be enough to result in distal regulation and a complex 3D organization, and likely also needs a favourable genomic context (expanded genome size with large intergenic regions and introns) as well as a specific evolutionary context (complex multicellular organisms) that may eventually exploit the expanded regulatory potential. In this regard, future insights into the molecular mechanisms responsible for the presence of long-range regulation and TAD-like structures in the genomes of certain plants with large genomes and distal enhancers, such as maize and cotton [129-135], will be of particular interest. 
5.3.2) Novel methyl-transferases and hypermethylated genomes: In two non-animal eukaryotic lineages, the dinoflagellate coral symbionts of the genus Symbiodinium and some Charophyte algae, there have been massive expansions of their complements of C5 cytosine methyl-transferase (DNMT) genes [136]. These genes have originated by several independent recruitments of DNMT domains by certain transposable elements that subsequently expanded and perhaps in certain cases became domesticated. Given the abundance and pervasive transcription of some of these DNMT-encoding Symbiodinium TEs and their ability to methylate CGs, it has been suggested that the extreme methylation content of $S$. kawagutii and $S$. minutum is likely the result of the appearance of these TEDNMT genes [136]. However, whether or not these changes have resulted in large organismal changes needs to be further investigated.

5.3.3) The microprocessor machinery and miRNA-based regulation: The origin of the microprocessor machinery is also a clear-cut example of quasa-reg that resulted in a new global regulatory feature: a global miRNA regulatory system. Interestingly, the two key proteins in this machinery, Drosha and Pasha, were long thought to be animal-specific; however, they have recently been identified in five different genera of Ichthyosporeans [137], another unicellular lineage closely related to animals. Furthermore, in three Ichthyosporean lineages, those within the genus Sphaeroforma, the authors demonstrated the presence of bona fide miRNAs with highly conserved genomic locations and expression profiles across the three species, adding further support to the evolutionary association between the presence of a complete microprocessor machinery and animal-type miRNA processing.

5.3.4) The eMIC domain and neural microexon programs: The evolution of extensive neuronal microexon programs in bilaterians due to the origin of a novel biochemical function is another recently described example. Microexons are very short (3-27 nucleotides) exons that were originally described to be highly included in mammalian neurons [138, 139]. Microexons encode a few aminoacids that are located at the surfaces of proteins with important neuronal functions, and often modulate protein-protein interactions. Given their minute size, they are not recognized in most cell types. However, post-mitotic neurons express a specific splicing factor, SRRM4, which enhances early spliceosomal recruitment and assembly around microexons, triggering their inclusion in neuronal transcripts [140, 141]. Large programs of neuronal microexons have now been found in nearly all bilaterian nervous systems, tracing their origin to bilaterian ancestors [141]. The emergence of these programs coincides with the origin of a new protein domain (termed enhancer of microexons, eMIC). Such domain is in fact necessary and sufficient to induce microexon inclusion in other cellular and phylogenetic contexts, suggesting a direct mechanistic and evolutionary connection. Strikingly, the eMIC domain originated as a novel bilaterian-specific alternative isoform of a pan-eukaryotic splicing factor (ortholog to SRRM2/SRm300 in humans), and it was further subfunctionalized in vertebrates after the WGDs [141]. Therefore, the origin of a domain with a new biochemical activity (the quasa-reg), allowed bilaterian species to expand and specialize their neuronal proteomes with a global regulatory program of microexons (the Type A feature).

5.3.5) Spliced RNA leaders and Spliced Leader Trans-Splicing (SLTS) and operon-like polycistronic gene expression: A variety of eukaryotic organisms, including several animal lineages, have recurrently evolved a particular elaboration of their spliceosomal splicing mechanism, the SLTS [142]. In SLTS, a short trans-encoded RNA "leader" sequence is 
attached to the 5' end of transcripts derived from a subset of genes located in other parts of the genome. Therefore, although it is generally assumed that the evolution of SLTS is probably the consequence of a mutational ratchet (i.e. upon the appearance of spliced leader-like sequences by neutral mutations, SLTS can become indispensable if their target transcripts lost their ancestral, non-SL dependent 5' UTRs)[143], SLTS has enabled new evolutionary paths for the emergence of a novel global gene expression regulatory mechanism.

In particular, SLTS is tightly linked with the appearance of another global regulatory feature: the operon-like polycistronic transcripts in several animal lineages such as nematodes [144] and tunicates [145]. In eukaryotes, in the absence of SLTS, polycistronic transcripts are extremely rare since the translation of the more downstream open reading frames within the transcript is very inefficient. The emergence of a SLTS system can overcome this problem since it can generate monocistronic mature mRNAs from polycistronic transcripts [146]. Thus, SLTS opens the possibility for the evolution of gene regulatory systems similar to those of bacterial operons, in which the expression of several genes is tightly coordinated by its shared transcription. Furthermore, the possibility of evolving operon-like transcripts also adds a new evolutionary meaning to those genomic rearrangements that create new gene neighbourhoods that are in a suitable (head to tail) orientation for the evolution of novel polycistronic transcripts.

5.4) Connection of independent regulatory layers. Recruiting or creating a single new target into a regulatory pathway or network is likely to have, in most cases, just a small incremental impact. Nonetheless, in some occasions, the recruitment of a new target will merge or interconnect two previously independent regulatory systems. That, in our view, will qualitatively expand the regulatory potential of the genome, since the resulting regulatory system will be more complex that the sum of the parts. While we acknowledge that the boundaries of this category are particularly diffuse and may be rampant depending on the limits (e.g. a gain of a miRNA binding site on a TF's 3'UTR could qualify for this category), we believe it is worth highlighting a few illustrative examples.

5.4.1) Connecting an AS regulatory program with a signalling pathway: Esrp is a family of RBPs that have been initially associated with epithelial cell types in mammals [147, 148]. It regulates a program of alternative exons in genes related to cell-cell adhesion, cytoskeleton, plasma membrane, among others, that allow the production of distinct isoforms in epithelial vs. mesenchymal cells [149]. One of the most important targets is the mutually exclusive exon skipping event present in the Fgf receptor (Fgfr) genes. These exons encode part of the third immunoglobulin domain of FGFR1, 2 and 3, and their inclusion confers the receptors different affinities for Fgf ligands $[150,151]$. The generation of these isoforms in specific cell types (epithelial vs. mesenchymal) has been crucial for the development of multiple structures, and a mouse model genetically forced to use only the mesenchymal isoform (exon IIIc) of Fgfr2 shows severe organogenesis defects [152]. A recent study showed that Esrp is associated with mesenchymal-to-epithelial transitions since, at least, the last common ancestor of deuterostomes [153]. However, there are very few conserved targets across distantly related groups. Instead, each Esrp network seems to have assembled independently in the different phyla. Interestingly, the Fgfr mutually exclusive exon evolved in chordate ancestors through an internal tandem exon duplication [153]. Such duplicated exon was soon recruited to the Esrp regulatory program [147, 153], 
interconnecting two previously independent regulatory systems (those having Esrp and Fgf as master regulators). As usual, although it is not possible to know whether the origin of this quasa-reg contributed to the origin of vertebrate structures, the interconnection between Esrp and Fgf regulatory modules is certainly now essential for the development of many of these structures.

5.4.2) Connecting a signalling and a mechanotransduction pathways: Gene regulation mediated by $\beta$-catenin has traditionally been exclusively associated with Wnt signalling. However, several recent works have shown that both Wnt ligands and $\beta$-catenin have also been acting independently of each other for a long time, probably since these two pathways originated in metazoan ancestors.

In the case of $\beta$-catenin, its transcriptional functions, including the activation of highly conserved targets such as Brachyury, can also be triggered by mechanotransduction, independently of the action of Wnt ligands and receptors [154, 155]. In the appropriate cellular contexts, cell straining by mechanical forces, such as those generated by morphogenetic movements during gastrulation, is sufficient to release $\beta$-catenin from cell junctions and its role in cell adhesion to be translocated to the nucleus and regulate gene expression [154]. Importantly, this $\beta$-catenin mechanotransduction pathway is extremely ancient, dating back at least to the last common ancestor of Cnidaria and Bilateria [155].

Regarding $\beta$-catenin-independent Wnt signalling, in recent years it is becoming apparent that non-canonical Wnt components are at least as ancient as the canonical ones. For instance, the Planar Cell Polarity (PCP) pathway is conserved between cnidarians and bilaterians [156-160]. And, although PCP has not been functionally studied in sponges yet, all core PCP components, including Fmi and Strabismus are present in the genomes of homoscleromorph sponges [161]. Furthermore, recent data from a freshwater sponge suggest that other non-canonical Wnt signalling modules may be present in this lineage as well [162].

Thus, if $\beta$-catenin-dependent mechanotransduction and non-canonical Wnt signalling have coexisted as two different regulatory layers since the origin of animals, perhaps these two pathways originally evolved separately and became mutually interconnected through the canonical Wnt/ $\beta$-catenin signalling only at a later stage. For instance, it could be speculated that $\beta$-catenin-dependent mechanotransduction could have evolved within the biological context and ecology of a unicellular lineage, where coupling a mechanosensitive system with transcriptional regulation could have been particularly advantageous. Thus, $\beta$-catenin mechanotransduction could be more ancient, appearing earlier than Wnt ligands and other secreted signalling molecules that are more typically associated with multicellularity. In these early stages of animal multicellularity, the newly originated Wnt ligands would have initially been involved in non-canonical Wnt signalling only, through the interaction with Frizzled receptors, which predate the origin of animals and were perhaps part of a canonical GPCR$G$ protein complex [163]. Later on, once $\beta$-catenin mechanotransduction and non-canonical Wnt signalling were both in place, the emergence of new protein interactions would have linked together these two previously independent regulatory layers, giving rise to the Wnt canonical pathway and the control of $\beta$-catenin by Wnt ligands as we know it. This way, an ancestral transcriptional regulatory program that so far depended exclusively on mechanical cues for its regulation ( $\beta$-catenin mechanotransduction) became also under the control of 
secreted signalling molecules (Wnt ligands), expanding the possibilities for the evolution of novel morphogenetic mechanisms. Importantly, the establishment of such a connection could have appeared relatively easily. The key proteins in the canonical Wnt pathway linking together $\beta$-catenin with the destruction complex and the Wnt receptor complex are Axin and Dishevelled. Although these two proteins are animal-specific [163], their constituent protein domains (such as DIX, PDZ, DEP and RGS) are much more ancient, with their corresponding Pfam accessions [164] containing members of many other eukaryotic lineages. Therefore, the mutual interconnections between these proteins could have emerged through modification of previously existing genes by mechanisms like exon shuffling and gene fusion (see Section 6). This way, the RGS domain (involved in the regulation of GPCR-G signalling) of a proto-axin gene could have been joined with a DIX domain (allowing the interaction with Dishevelled, where DIX is also present) and with the GSK3 and $\beta$-catenin interaction domains. Unfortunately, this hypothesis is currently impossible to demonstrate. The Wnt- $\beta$-catenin connection of the canonical Wnt pathway seems to date back to at least the last common ancestor of metazoans $[165,166]$. On the other hand, key components of both $\beta$-catenin mechanotransduction and Wnt signalling (including $\beta$-catenin and Wnt and the aforementioned Axin and Dishevelled) are not present in the genomes of animal unicellular relatives or any other eukaryotic lineage $[113,163$, 167]. Thus, there is currently no known lineage that could have maintained an ancestral intermediate step to test the previous evolutionary scenario. Still, even as a hypothetical case, this could be an interesting example of how two different regulatory layers could be connected in evolution creating new routes for the emergence of morphogenetic and regulatory innovations.

\section{Mechanisms underlying the evolution of quasa-regs}

While the first two types of genomic factors discussed above may have a more global impact on genomic regulatory potential, we suggest that quasa-regs, given that they are usually caused by relatively small mutations, are a more common drive for macroevolutionary change. What are the evolutionary molecular mechanisms behind the origin of quasa-regs? It is possible that, in some cases, quasa-regs originate from raw genomic sequence. Nonetheless, it is more likely that in many instances they evolve, at least in part, from preexisting functional elements. In particular, gene duplication followed by neofunctionalization of one of the copies is probably behind the origin of many quasa-regs. Gene duplication provides the raw material for new gene functions to evolve without compromising the ancestral ones. This is the case for classic TF and RBP subfamily diversification (Section $5.1)$.

Related to gene duplication is the emergence of novel (regulatory) functions by AS. Through the evolution of new alternative isoforms within pre-existing genes, the original functions are still preserved by the ancestral isoform(s). Therefore, the newly alternatively spliced sequence, usually expressed at low levels, can freely evolve without selected constraints [168]. In fact, gene duplication and AS have often been regarded as highly complementary in evolutionary terms, and their prevalence is inversely correlated ([169] although see [170]). This complementarity is particularly evident in the case of intragenic duplications of specific 
exons, such as the case of FOXP1 (Section 5.2) or FGFR (Section 5.4.1), and may be referred to as internal paralogy [171].

Another key mechanism for the origin of quasa-regs is exon shuffling. Through this process, previously independent protein domains end up forming new genes with novel domain combinations and, often, protein functions. This might be the source, for example, for the origin of multidomain proteins such as Dishevelled or Axin (Section 5.4.2). While the mechanisms of exon shuffling are largely mysterious, genome comparisons across eukaryotes indicate its prevalence is rampant with dozens of new domain combinations found in any sequenced lineage [163, 167, 172]. Adding exons derived from domesticated TEs is probably a main source for incorporating new domain combinations, such as in the case of Pax homedomain genes [102] and SCAN zinc fingers [173]. Interestingly, this can happen on the other direction too, with certain transposable elements capturing protein domains from the host, as in the capture of DNMT domains by TEs of dinoflagellates and charophytes [136] (Section 5.3.2). Moreover, it is also possible that mechanisms such as exon skipping may allow the resolution of read-through transcription and chimeric transcripts between two genes in the same orientation into a single gene fusion with a mixed complement of protein domains (as in Zn-finger homeobox genes). Most likely, gene duplication is also crucial to provide the raw material for exon shuffling to occur and for the generation of chimeric transcripts between tandemly duplicated genes. The result of these gene fusions would be novel proteins containing different numbers of repetitions of the same domain. This is particularly frequent in the case of massive gene clusters such as those formed by zinc fingers, which can have from two to forty zinc fingers and constitute a potential source for the evolution of architectural proteins such as CTCF (Section 5.3.1).

\section{Discussion and conclusions}

In this Chapter, we grouped several different types of genomic changes under a common umbrella and proposed that they may have exceptional importance as genomic factors underlying macroevolutionary processes. In particular, our unifying theme is that these factors produce a qualitative expansion in the regulatory potential of genomes. In this Section, we now acknowledge and discuss several limitations and caveats of our proposal.

First, the explicit purpose of this Chapter was to introduce new ideas and concepts, ideally risky and unconventional ones. Therefore, we acknowledge beforehand that some proposals may not hold. This Chapter should be taken as food for thought for any reader interested in these evolutionary topics.

Second, as discussed above, the boundaries among the three proposed Types (and further subtypes) are diffuse in many cases. However, this should not affect their inclusion under the common umbrella we defined.

Third, we do not attempt to argue that these types of changes are more or less important in (macro)evolution than other changes that we regard as quantitatively modifying genome's regulatory potential. Indeed, it is likely that quantitative changes in regulation are much more common, particularly across shorter evolutionary scales. Also, not every important change 
must be regulatory. Certainly, numerous examples of changes in terminal genes have been shown to have crucial importance in evolution at different organismal levels.

Fourth, while the specific cases we discuss in each category are likely to have a significant impact on organismal evolution, it is not possible to distinguish which of those changes and factors are really "drivers" or "passengers" of the macroevolutionary processes, or even which were essential for them to have occurred. It is possible (perhaps even common) that genes or isoforms that are now essential for a given lineage were neutral for dozens of generations, despite already conferring the ability to expand the regulatory potentials, as mentioned above. As with any mutation, the short- and mid-term functional impact of these changes will probably be impossible to elucidate. Moreover, it is likely that unique combinations of external factors have also been required for the fixation of these genomic factors in evolutionary history.

Finally, we believe that these genomic changes are more compatible with a relatively gradual evolutionary process. Or, in other words, they are not expected to cause "hopeful monsters", as proposed for classic macro-mutations or mutations with macroevolutionary effects. The changes that we discuss may be nearly neutral in origin (since the ancestral regulatory modules are maintained), but we propose that they have the effect of boosting the evolutionary process by providing a qualitative expansion on the regulatory abilities of the genome. In this regard, these genomic changes should be regarded as "game changers" that open new highways for genome and organismal evolution.

\section{Acknowledgements}

We would like to thank Alex de Mendoza, María Almuedo-Castillo, Rafael D. Acemel, Arnau Sebé-Pedrós and Isabel Almudí for insightful scientific discussions and critical comments on the manuscript. We are especially grateful to Alex de Mendoza for sharing unpublished data on the evolution of YY1 genes in animals. The authors are funded by the Spanish Ministerio de Economía y Competitividad (RYC-2016-20089 to I.M., BFU2014-55076-P and BFU201789201-P to M.I.) and by the European Research Council (ERC) under the European Union's Seventh Framework Program FP7 research and innovation program (ERC-StG-LS2-637591 to M.I). 


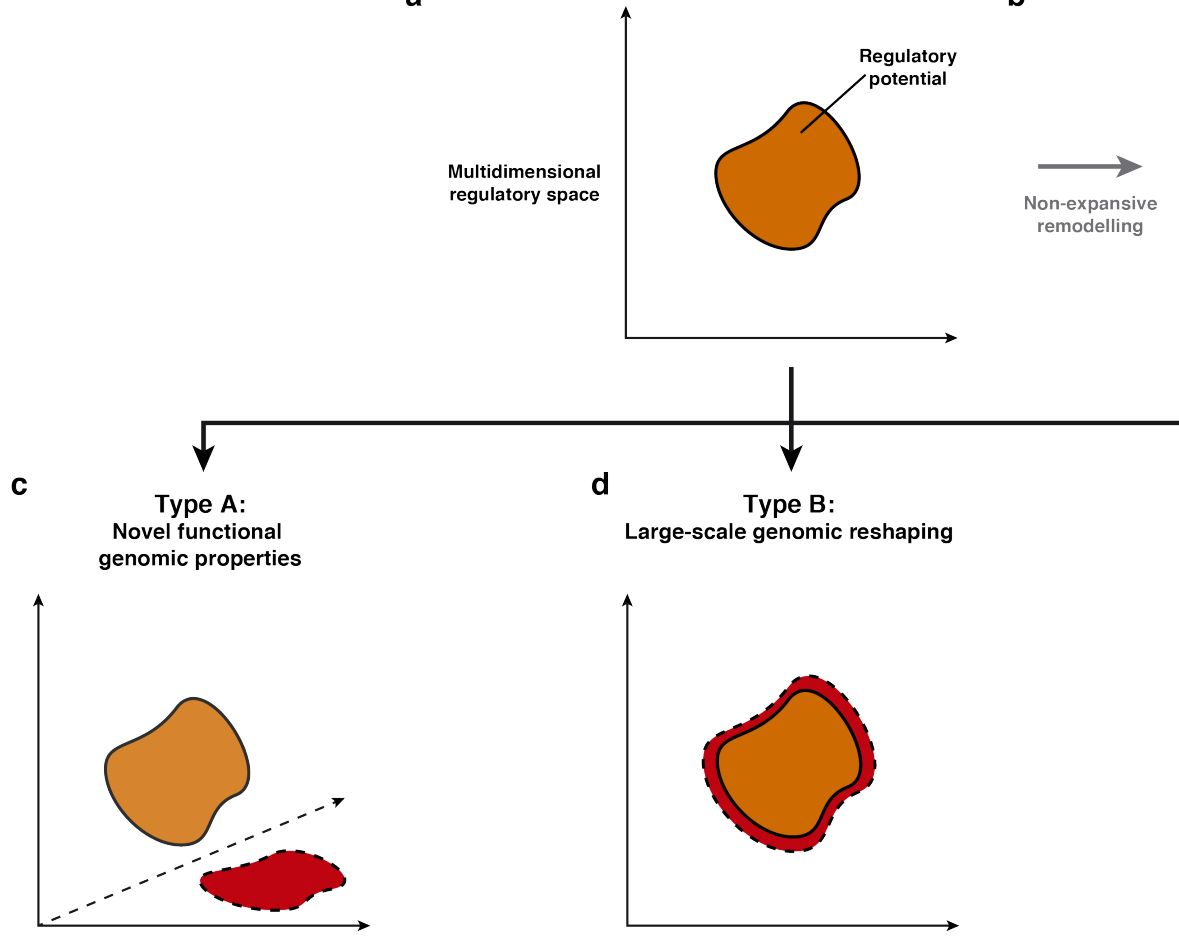

Figure 1. Expansion of the regulatory potential during evolution.

a) Within a hypothetical multidimensional regulatory space (represented here by just two axes for simplification), only a limited fraction of the space can be effectively explored during the evolution of a given species. This fraction of the regulatory space (orange shape) defines the regulatory potential of the species. b) The regulatory potential can be substantially modified and reshaped without increasing the fraction of multidimensional regulatory space available for evolutionary exploration. c) Type A factors change global genomic properties, allowing new ways of encoding and interpreting regulatory information; thus, they can be viewed as the addition of a new axis through which the regulatory potential of a species can be explored. d) Type B changes have large-scale pan-genomic effects, which can result in broad expansions of the regulatory potential. e) Type $C$ refers to changes that can be considered as small from a genomic perspective but that instantly open for exploration new sections of the regulatory space, bridging and expanding sections of the pre-existing regulatory potential.

Figure 2

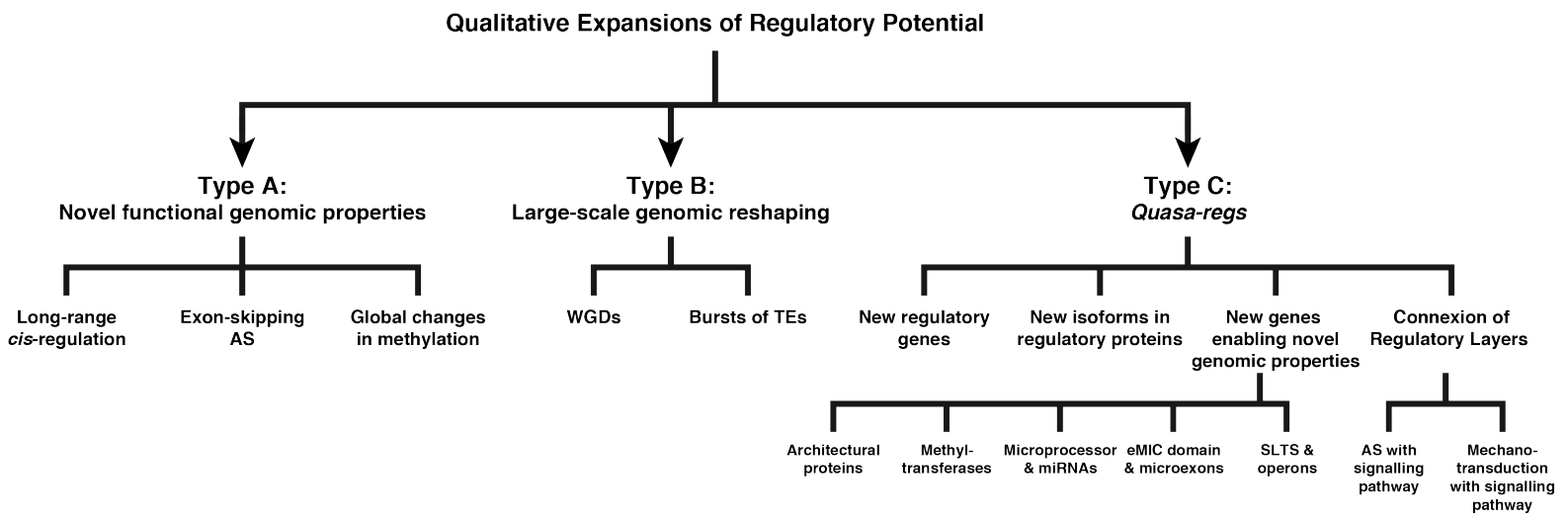

Figure 2. Genomic changes associated to macroevolution: types of genetic factors that qualitatively expand genome regulatory potentials. 


\section{References}

1. Erwin $\mathrm{DH}$ : Developmental push or environmental pull? The causes of macroevolutionary dynamics. Hist Philos Life Sci 2017, 39:36.

2. Muscente AD, Prabhu A, Zhong H, Eleish A, Meyer MB, Fox P, Hazen RM, Knoll AH: Quantifying ecological impacts of mass extinctions with network analysis of fossil communities. Proc Natl Acad Sci U S A 2018, 115:5217-5222.

3. Crampton JS, Meyers SR, Cooper RA, Sadler PM, Foote M, Harte D: Pacing of Paleozoic macroevolutionary rates by Milankovitch grand cycles. Proc Natl Acad Sci U S A 2018, 115:5686-5691.

4. Albalat R, Canestro C: Evolution by gene loss. Nat Rev Genet 2016, 17:379-391.

5. Garcia-Fernàndez J: The genesis and evolution of homeobox gene clusters. Nat Rev Genet 2005, 6:881-892.

6. DuBuc TQ, Stephenson TB, Rock AQ, Martindale MQ: Hox and Wnt pattern the primary body axis of an anthozoan cnidarian before gastrulation. Nat Commun 2018, 9:2007.

7. He S, Del Viso F, Chen CY, Ikmi A, Kroesen AE, Gibson MC: An axial Hox code controls tissue segmentation and body patterning in Nematostella vectensis. Science 2018, 361:1377-1380.

8. Heger $\mathrm{P}$, Marin B, Bartkuhn M, Schierenberg E, Wiehe T: The chromatin insulator CTCF and the emergence of metazoan diversity. Proc Natl Acad Sci USA 2012, 109:17507-17512.

9. Acemel RD, Maeso I, Gomez-Skarmeta JL: Topologically associated domains: a successful scaffold for the evolution of gene regulation in animals. Wiley Interdiscip Rev Dev Biol 2017, 6.

10. Maeso I, Acemel RD, Gomez-Skarmeta JL: Cis-regulatory landscapes in development and evolution. Curr Opin Genet Dev 2017, 43:17-22.

11. Irimia M, Maeso I, Roy SW, Fraser HB: Ancient cis-regulatory constraints and the evolution of genome architecture. Trends Genet 2013, 29:521-528.

12. Deline B, Greenwood JM, Clark JW, Puttick MN, Peterson KJ, Donoghue PCJ: Evolution of metazoan morphological disparity. Proc Natl Acad Sci U S A 2018, 115:E8909-E8918.

13. Peterson $\mathrm{KJ}$, Dietrich MR, McPeek MA: MicroRNAs and metazoan macroevolution: insights into canalization, complexity, and the Cambrian explosion. Bioessays 2009, 31:736-747.

14. Moran Y, Agron M, Praher D, Technau U: The evolutionary origin of plant and animal microRNAs. Nat Ecol Evol 2017, 1:27.

15. Nelson C, Hersh B, Carroll S: The regulatory content of intergenic DNA shapes genome architecture. Genome Biology 2004, 5:R25.

16. Harmston N, Ing-Simmons E, Tan G, Perry M, Merkenschlager M, Lenhard B: Topologically associating domains are ancient features that coincide with Metazoan clusters of extreme noncoding conservation. Nat Commun 2017, 8:441.

17. Sebe-Pedros A, Ballare C, Parra-Acero H, Chiva C, Tena JJ, Sabido E, GomezSkarmeta JL, Di Croce L, Ruiz-Trillo I: The Dynamic Regulatory Genome of Capsaspora and the Origin of Animal Multicellularity. Cell 2016, 165:1224-1237.

18. Irimia M, Tena JJ, Alexis MS, Fernandez-Miñan A, Maeso I, Bogdanovic O, de la Calle-Mustienes E, Roy SW, Gómez-Skarmeta JL, Fraser HB: Extensive conservation of ancient microsynteny across metazoans due to cis-regulatory constraints. Genome Res 2012, 22:2356-2367. 
19. Marlétaz F, Firbas PN, Maeso I, Tena JJ, Bogdanovic O, Perry M, Wyatt CD, de la Calle-Mustienes E, Bertrand S, Burguera D, et al: Amphioxus functional genomics and the origins of vertebrate gene regulation. Nature 2018, In press.

20. Rao SS, Huntley MH, Durand NC, Stamenova EK, Bochkov ID, Robinson JT, Sanborn AL, Machol I, Omer AD, Lander ES, Aiden EL: A 3D map of the human genome at kilobase resolution reveals principles of chromatin looping. Cell 2014, 159:1665-1680.

21. Nora EP, Goloborodko A, Valton AL, Gibcus JH, Uebersohn A, Abdennur N, Dekker J, Mirny LA, Bruneau BG: Targeted Degradation of CTCF Decouples Local Insulation of Chromosome Domains from Genomic Compartmentalization. Cell 2017, 169:930-944 e922.

22. Sanborn AL, Rao SS, Huang SC, Durand NC, Huntley MH, Jewett AI, Bochkov ID, Chinnappan D, Cutkosky A, Li J, et al: Chromatin extrusion explains key features of loop and domain formation in wild-type and engineered genomes. Proc Natl Acad Sci U S A 2015, 112:E6456-6465.

23. Fudenberg G, Imakaev M, Lu C, Goloborodko A, Abdennur N, Mirny LA: Formation of Chromosomal Domains by Loop Extrusion. Cell Rep 2016, 15:2038-2049.

24. Franke M, Ibrahim DM, Andrey G, Schwarzer W, Heinrich V, Schopflin R, Kraft K, Kempfer R, Jerkovic I, Chan WL, et al: Formation of new chromatin domains determines pathogenicity of genomic duplications. Nature 2016, 538:265-269.

25. Lupianez DG, Kraft K, Heinrich V, Krawitz P, Brancati F, Klopocki E, Horn D, Kayserili $H$, Opitz JM, Laxova $R$, et al: Disruptions of topological chromatin domains cause pathogenic rewiring of gene-enhancer interactions. Cell 2015, 161:1012-1025.

26. Symmons O, Pan L, Remeseiro S, Aktas T, Klein F, Huber W, Spitz F: The Shh Topological Domain Facilitates the Action of Remote Enhancers by Reducing the Effects of Genomic Distances. Dev Cell 2016, 39:529-543.

27. Heger $P$, Wiehe $T$ : New tools in the box: an evolutionary synopsis of chromatin insulators. Trends Genet 2014, 30:161-171.

28. Rowley MJ, Nichols MH, Lyu X, Ando-Kuri M, Rivera ISM, Hermetz K, Wang P, Ruan Y, Corces VG: Evolutionarily Conserved Principles Predict 3D Chromatin Organization. Mol Cell 2017, 67:837-852 e837.

29. Heger $\mathrm{P}$, George R, Wiehe T: Successive gain of insulator proteins in arthropod evolution. Evolution 2013, 67:2945-2956.

30. Pauli T, Vedder L, Dowling D, Petersen M, Meusemann K, Donath A, Peters RS, Podsiadlowski L, Mayer C, Liu S, et al: Transcriptomic data from panarthropods shed new light on the evolution of insulator binding proteins in insects : Insect insulator proteins. BMC Genomics 2016, 17:861.

31. Crane E, Bian Q, McCord RP, Lajoie BR, Wheeler BS, Ralston EJ, Uzawa S, Dekker $\mathrm{J}$, Meyer BJ: Condensin-driven remodelling of $\mathrm{X}$ chromosome topology during dosage compensation. Nature 2015, 523:240-244.

32. Heger $P$, Marin $B$, Schierenberg $E$ : Loss of the insulator protein CTCF during nematode evolution. BMC Mol Biol 2009, 10:84.

33. Jabbari K, Heger $\mathrm{P}$, Sharma R, Wiehe $\mathrm{T}$ : The Diverging Routes of BORIS and CTCF: An Interactomic and Phylogenomic Analysis. Life (Basel) 2018, 8.

34. Gaiti F, Calcino AD, Tanurdzic M, Degnan BM: Origin and evolution of the metazoan non-coding regulatory genome. Dev Biol 2017, 427:193-202.

35. Gaiti F, Jindrich K, Fernandez-Valverde SL, Roper KE, Degnan BM, Tanurdzic M: Landscape of histone modifications in a sponge reveals the origin of animal cis-regulatory complexity. Elife 2017, 6.

36. Grau-Bove X, Torruella G, Donachie S, Suga H, Leonard G, Richards TA, Ruiz-Trillo I: Dynamics of genomic innovation in the unicellular ancestry of animals. Elife 2017, 6. 
37. Schwaiger M, Schonauer A, Rendeiro AF, Pribitzer C, Schauer A, Gilles AF, Schinko $\mathrm{JB}$, Renfer E, Fredman D, Technau U: Evolutionary conservation of the eumetazoan gene regulatory landscape. Genome Res 2014, 24:639-650.

38. Rao SSP, Huang SC, Glenn St Hilaire B, Engreitz JM, Perez EM, Kieffer-Kwon KR, Sanborn AL, Johnstone SE, Bascom GD, Bochkov ID, et al: Cohesin Loss Eliminates All Loop Domains. Cell 2017, 171:305-320 e324.

39. Schwarzer W, Abdennur N, Goloborodko A, Pekowska A, Fudenberg G, Loe-Mie Y, Fonseca NA, Huber W, C HH, Mirny L, Spitz F: Two independent modes of chromatin organization revealed by cohesin removal. Nature 2017, 551:51-56.

40. Hug CB, Grimaldi AG, Kruse K, Vaquerizas JM: Chromatin Architecture Emerges during Zygotic Genome Activation Independent of Transcription. Cell 2017, 169:216-228 e219.

41. Kikuta $H$, Laplante $M$, Navratilova $P$, Komisarczuk AZ, Engstrom PG, Fredman D, Akalin A, Caccamo M, Sealy I, Howe K, et al: Genomic regulatory blocks encompass multiple neighboring genes and maintain conserved synteny in vertebrates. Genome Res 2007, 17:545-555.

42. Engstrom PG, Ho Sui SJ, Drivenes O, Becker TS, Lenhard B: Genomic regulatory blocks underlie extensive microsynteny conservation in insects. Genome Res 2007, 17:1898-1908.

43. Maeso I, Irimia M, Tena JJ, González-Pérez E, Tran D, Ravi V, Venkatesh B, Campuzano S, Gómez-Skarmeta JL, Garcia-Fernàndez J: An ancient genomic regulatory block conserved across bilaterians and its dismantling in tetrapods by retrogene replacement. Genome Res 2012, 22:642-655.

44. Canela A, Maman Y, Jung S, Wong N, Callen E, Day A, Kieffer-Kwon KR, Pekowska A, Zhang $H$, Rao SSP, et al: Genome Organization Drives Chromosome Fragility. Cell 2017, 170:507-521 e518.

45. Acemel RD, Tena JJ, Irastorza-Azcarate I, Marletaz F, Gomez-Marin C, de la CalleMustienes E, Bertrand S, Diaz SG, Aldea D, Aury JM, et al: A single threedimensional chromatin compartment in amphioxus indicates a stepwise evolution of vertebrate Hox bimodal regulation. Nat Genet 2016, 48:336-341.

46. Irimia M, Royo JL, Burguera D, Maeso I, Gómez-Skarmeta JL, Garcia-Fernandez J: Comparative genomics of the Hedgehog loci in chordates and the origins of Shh regulatory novelties. Sci Rep 2012, 2:433.

47. Letelier J, de la Calle-Mustienes E, Pieretti J, Naranjo S, Maeso I, Nakamura T, Pascual-Anaya J, Shubin NH, Schneider I, Martinez-Morales JR, Gomez-Skarmeta $\mathrm{JL}:$ A conserved Shh cis-regulatory module highlights a common developmental origin of unpaired and paired fins. Nat Genet 2018, 50:504-509.

48. Letelier J, Terriente J, Belzunce I, Voltes A, Undurraga CA, Polvillo R, Devos L, Tena $\mathrm{JJ}$, Maeso I, Retaux S, et al: Evolutionary emergence of the rac3b/rfng/sgca regulatory cluster refined mechanisms for hindbrain boundaries formation. Proc Natl Acad Sci U S A 2018, 115:E3731-E3740.

49. Grau-Bove X, Ruiz-Trillo I, Irimia M: Origin of exon skipping-rich transcriptomes in animals driven by evolution of gene architecture. Genome Biol 2018, 19:135.

50. Irimia M, Roy SW: Origin of spliceosomal introns and alternative splicing. Cold Spring Harb Perspect Biol 2014, 6:pii: a016071.

51. Kelemen $O$, Convertini $P$, Zhang Z, Wen Y, Shen M, Falaleeva M, Stamm S: Function of alternative splicing. Gene 2013, 514:1-30.

52. Stamm S, Ben-Ari S, Rafalska I, Tang Y, Zhang Z, Toiber D, Thanaraj TA, Soreq H: Function of alternative splicing. Gene 2005, 344:1-20.

53. Bhuiyan SA, Ly S, Phan M, Huntington B, Hogan E, Liu CC, Liu J, Pavlidis P: Systematic evaluation of isoform function in literature reports of alternative splicing. BMC Genomics 2018, 19:637.

54. Ellis JD, Barrios-Rodiles M, Colak R, Irimia M, Kim T, Calarco JA, Wang X, Pan Q, O'Hanlon D, Kim PM, et al: Tissue-specific alternative splicing remodels proteinprotein interaction networks. Mol Cell 2012, 46:884-892. 
55. Buljan M, Chalancon G, Eustermann S, Wagner GP, Fuxreiter M, Bateman A, Babu MM: Tissue-specific splicing of disordered segments that embed binding motifs rewires protein interaction networks. Mol Cell 2012, 46:871-883.

56. Yang X, Coulombe-Huntington J, Kang S, Sheynkman GM, Hao T, Richardson A, Sun S, Yang F, Shen YA, Murray RR, et al: Widespread Expansion of Protein Interaction Capabilities by Alternative Splicing. Cell 2016, 164:805-817.

57. Irimia $\mathrm{M}$, Blencowe $\mathrm{BJ}$ : Alternative splicing: decoding an expansive regulatory layer. Curr Opin Cell Biol 2012, 24:323-332.

58. Kalsotra A, Cooper TA: Functional consequences of developmentally regulated alternative splicing. Nat Rev Genet 2011, 12:715-729.

59. Jensen KB, Dredge BK, Stefani G, Zhong R, Buckanovich RJ, Okano HJ, Yang YY, Darnell RB: Nova-1 regulates neuron-specific alternative splicing and is essential for neuronal viability. Neuron 2000, 25:359-371.

60. Li Q, Zheng S, Han A, Lin CH, Stoilov P, Fu XD, Black DL: The splicing regulator PTBP2 controls a program of embryonic splicing required for neuronal maturation. Elife 2014, 3:e01201.

61. Licatalosi DD, Yano M, Fak JJ, Mele A, Grabinski SE, Zhang C, Darnell RB: Ptbp2 represses adult-specific splicing to regulate the generation of neuronal precursors in the embryonic brain. Genes Dev 2012, 26:626-642.

62. Gehman LT, Stoilov P, Maguire J, Damianov A, Lin CH, Shiue L, Ares M, Jr, Mody I, Black DL: The splicing regulator Rbfox1 (A2BP1) controls neuronal excitation in the mammalian brain. Nat Genet 2011, 43:706-711.

63. Gehman LT, Meera P, Stoilov P, Shiue L, O'Brien JE, Meisler MH, Ares M Jr, Otis TS, Black DL: The splicing regulator Rbfox 2 is required for both cerebellar development and mature motor function. Genes Dev 2012, 26:445-460.

64. Quesnel-Vallières $M$, Irimia M, Cordes SP, Blencowe BJ: Essential roles for the splicing regulator nSR100/SRRM4 during nervous system development. Genes Dev 2015, 29:746-759.

65. Barbosa-Morais NL, Irimia M, Pan Q, Xiong HY, Gueroussov S, Lee LJ, Slobodeniuc $\mathrm{V}$, Kutter $\mathrm{C}$, Watt $\mathrm{S}$, Colak $\mathrm{R}$, et al: The evolutionary landscape of alternative splicing in vertebrate species. Science 2012, 338:1587-1593.

66. Maniatis T, Tasic B: Alternative pre-mRNA splicing and proteome expansion in metazoans. Nature 2002, 418:236-243.

67. Blencowe BJ: Alternative Splicing: New Insights from Global Analyses. Cell 2006, 126:37-47.

68. Lev-Maor G, Sorek R, Shomron N, Ast G: The birth of an alternatively spliced exon: 3' splice-site selection in Alu exons. Science 2003, 300:1288-1291.

69. Sorek R, Lev-Maor G, Reznik M, Dagan T, Belinky F, Graur D, Ast G: Minimal Conditions for Exonization of Intronic Sequences: 5' Splice Site Formation in Alu Exons. Mol Cell 2004, 14:221-231.

70. Lev-Maor G, Ram O, Kim E, Sela N, Goren A, Levanon EY, G. A: Intronic Alus influence alternative splicing. PLoS Genet 2008, 4:e1000204.

71. Keren H, Lev-Maor G, Ast G: Alternative splicing and evolution: diversification, exon definition and function. Nat Rev Genet 2010, 11:345-355.

72. Merkin JJ, Chen P, Alexis MS, Hautaniemi SK, Burge CB: Origins and impacts of new mammalian exons. 102015.

73. Alekseyenko AV, Kim N, Lee CJ: Global analysis of exon creation versus loss and the role of alternative splicing in 17 vertebrate genomes. RNA 2007, 13:661-670.

74. Ram O, Ast G: SR proteins: a foot on the exon before the transition from intron to exon definition. Trends Genet 2007, 23:5-7.

75. Robberson BL, Cote GJ, Berget SM: Exon definition may facilitate splice site selection in RNAs with multiple exons. Mol Cell Biol 1990, 10:84 - 94.

76. De Conti $\mathrm{L}$, Baralle M, Buratti $\mathrm{E}$ : Exon and intron definition in pre-mRNA splicing. Wiley Interdiscip Rev RNA 2013, 4:49-60. 
77. Barbosa-Morais NL, Carmo-Fonseca M, Aparicio S: Systematic genome-wide annotation of spliceosomal proteins reveals differential gene family expansion. Genome Res 2006, 16:66-77.

78. Irimia M, Maeso I, Burguera D, Hidalgo-Sánchez M, Puelles L, Garcia-Fernàndez J, Roy SW, Ferran JL: Contrasting 5' and 3' Evolutionary Histories and Frequent Evolutionary Convergence in Meis/hth Gene Structures. Genome Biol Evol 2011, 3:551-564.

79. Feng S, Cokus SJ, Zhang X, Chen PY, Bostick M, Goll MG, Hetzel J, Jain J, Strauss $\mathrm{SH}$, Halpern ME, et al: Conservation and divergence of methylation patterning in plants and animals. Proc Natl Acad Sci U S A 2010, 107:8689-8694.

80. Zemach A, McDaniel IE, Silva P, Zilberman D: Genome-wide evolutionary analysis of eukaryotic DNA methylation. Science 2010, 328:916-919.

81. Bogdanović O, Smits AH, de la Calle Mustienes E, Tena JJ, Ford E, Williams R, Senanayake U, Schultz MD, Hontelez S, van Kruijsbergen I, et al: Active DNA demethylation at enhancers during the vertebrate phylotypic period. Nat Genet 2016, 48:417-426.

82. Huang S, Chen Z, Yan X, Yu T, Huang G, Yan Q, Pontarotti PA, Zhao H, Li J, Yang $P$, et al: Decelerated genome evolution in modern vertebrates revealed by analysis of multiple lancelet genomes. Nat Commun 2014, 5:5896.

83. Maeso I, Roy SW, Irimia M: Widespread recurrent evolution of genomic features. Genome Biol Evol 2012, 4:486-500.

84. Wood TE, Takebayashi N, Barker MS, Mayrose I, Greenspoon PB, Rieseberg LH: The frequency of polyploid speciation in vascular plants. Proc Natl Acad Sci U S A 2009, 106:13875-13879.

85. Soltis PS, Marchant DB, Van de Peer Y, Soltis DE: Polyploidy and genome evolution in plants. Curr Opin Genet Dev 2015, 35:119-125.

86. Clark JW, Donoghue PCJ: Whole-Genome Duplication and Plant Macroevolution. Trends Plant Sci 2018, 23:933-945.

87. Flot JF, Hespeels B, Li X, Noel B, Arkhipova I, Danchin EG, Hejnol A, Henrissat B, Koszul R, Aury JM, et al: Genomic evidence for ameiotic evolution in the bdelloid rotifer Adineta vaga. Nature 2013, 500:453-457.

88. Kenny NJ, Chan KW, Nong W, Qu Z, Maeso I, Yip HY, Chan TF, Kwan HS, Holland $\mathrm{PW}$, Chu $\mathrm{KH}$, Hui $\mathrm{JH}$ : Ancestral whole-genome duplication in the marine chelicerate horseshoe crabs. Heredity (Edinb) 2016, 116:190-199.

89. Nossa CW, Havlak P, Yue JX, Lv J, Vincent KY, Brockmann HJ, Putnam NH: Joint assembly and genetic mapping of the Atlantic horseshoe crab genome reveals ancient whole genome duplication. Gigascience 2014, 3:9.

90. Schwager EE, Sharma PP, Clarke T, Leite DJ, Wierschin T, Pechmann M, AkiyamaOda Y, Esposito L, Bechsgaard J, Bilde T, et al: The house spider genome reveals an ancient whole-genome duplication during arachnid evolution. BMC Biol 2017, 15:62.

91. Putnam N, Butts T, Ferrier DEK, Furlong RF, Hellsten U, Kawashima T, RobinsonRechavi M, Shoguchi E, Terry A, Yu JK, et al: The amphioxus genome and the evolution of the chordate karyotype. Nature 2008, 453:1064-1071.

92. Donoghue PC, Purnell MA: Genome duplication, extinction and vertebrate evolution. Trends Ecol Evol 2005, 20:312-319.

93. Clarke JT, Lloyd GT, Friedman M: Little evidence for enhanced phenotypic evolution in early teleosts relative to their living fossil sister group. Proc Natl Acad Sci U S A 2016, 113:11531-11536.

94. Laurent $S$, Salamin N, Robinson-Rechavi M: No evidence for the radiation time lag model after whole genome duplications in Teleostei. PLoS One 2017, 12:e0176384.

95. Thompson JN, Merg KF: Evolution of Polyploidy and The Diversification of Plant-Pollinator Interactions. Ecology 2008, 89:2197-2206. 
96. Kennedy B, Sabara H, Haydon D, Husband B: Pollinator-mediated assortative mating in mixed ploidy populations of Chamerion angustifolium (Onagraceae). Oecologia 2006, 150:398-408.

97. Fawcett JA, Maere S, Van de Peer Y: Plants with double genomes might have had a better chance to survive the Cretaceous-Tertiary extinction event. Proc Natl Acad Sci USA 2009, 106:5737-5742.

98. Cañestro $\mathrm{C}$, Albalat R, Irimia M, Garcia-Fernàndez J: Impact of gene gains, losses and duplication modes on the origin and diversification of vertebrates. Semin Cell Dev Biol 2013:doi:pii: S1084-9521(1012)00232-00237. 00210.01016/j.semcdb.02012.00212.00008.

99. Carbone L, Harris RA, Gnerre S, Veeramah KR, Lorente-Galdos B, Huddleston J, Meyer TJ, Herrero J, Roos C, Aken B, et al: Gibbon genome and the fast karyotype evolution of small apes. Nature 2014, 513:195-201.

100. Harrison MC, Jongepier E, Robertson HM, Arning N, Bitard-Feildel T, Chao H, Childers CP, Dinh H, Doddapaneni H, Dugan S, et al: Hemimetabolous genomes reveal molecular basis of termite eusociality. Nat Ecol Evol 2018, 2:557-566.

101. Ashley J, Cordy B, Lucia D, Fradkin LG, Budnik V, Thomson T: Retrovirus-like Gag Protein Arc1 Binds RNA and Traffics across Synaptic Boutons. Cell 2018, 172:262-274 e211.

102. Breitling R, Gerber JK: Origin of the paired domain. Dev Genes Evol 2000, 210:644-650.

103. Cornelis G, Funk M, Vernochet C, Leal F, Tarazona OA, Meurice G, Heidmann O, Dupressoir A, Miralles A, Ramirez-Pinilla MP, Heidmann T: An endogenous retroviral envelope syncytin and its cognate receptor identified in the viviparous placental Mabuya lizard. Proc Natl Acad Sci U S A 2017, 114:E10991E11000.

104. Lavialle C, Cornelis G, Dupressoir A, Esnault C, Heidmann O, Vernochet C, Heidmann T: Paleovirology of 'syncytins', retroviral env genes exapted for a role in placentation. Philos Trans $R$ Soc Lond B Biol Sci 2013, 368:20120507.

105. Pastuzyn ED, Day CE, Kearns RB, Kyrke-Smith M, Taibi AV, McCormick J, Yoder N, Belnap DM, Erlendsson S, Morado DR, et al: The Neuronal Gene Arc Encodes a Repurposed Retrotransposon Gag Protein that Mediates Intercellular RNA Transfer. Cell 2018, 172:275-288 e218.

106. Trizzino M, Kapusta A, Brown CD: Transposable elements generate regulatory novelty in a tissue-specific fashion. BMC Genomics 2018, 19:468.

107. Maeso I, Tena JJ: Favorable genomic environments for cis-regulatory evolution: A novel theoretical framework. Semin Cell Dev Biol 2016, 57:2-10.

108. Jordan IK, Rogozin IB, Glazko GV, Koonin EV: Origin of a substantial fraction of human regulatory sequences from transposable elements. Trends Genet 2003, 19:68-72.

109. Lynch VJ, Leclerc RD, May G, Wagner GP: Transposon-mediated rewiring of gene regulatory networks contributed to the evolution of pregnancy in mammals. Nat Genet 2011, 43:1154-1159.

110. Lynch VJ, Nnamani MC, Kapusta A, Brayer K, Plaza SL, Mazur EC, Emera D, Sheikh SZ, Grutzner F, Bauersachs S, et al: Ancient transposable elements transformed the uterine regulatory landscape and transcriptome during the evolution of mammalian pregnancy. Cell Rep 2015, 10:551-561.

111. Kunarso G, Chia NY, Jeyakani J, Hwang C, Lu X, Chan YS, Ng HH, Bourque G: Transposable elements have rewired the core regulatory network of human embryonic stem cells. Nat Genet 2011, 42:631-634.

112. Bejerano G, Lowe CB, Ahituv N, King B, Siepel A, Salama SR, Rubin EM, James Kent W, Haussler D: A distal enhancer and an ultraconserved exon are derived from a novel retroposon. Nature 2006, 441:87-90.

113. Richter DJ, Fozouni P, Eisen MB, King N: Gene family innovation, conservation and loss on the animal stem lineage. Elife 2018, 7. 
114. Paps J, Holland PWH: Reconstruction of the ancestral metazoan genome reveals an increase in genomic novelty. Nat Commun 2018, 9:1730.

115. de Mendoza A, Sebe-Pedros A, Sestak MS, Matejcic M, Torruella G, Domazet-Loso T, Ruiz-Trillo I: Transcription factor evolution in eukaryotes and the assembly of the regulatory toolkit in multicellular lineages. Proc Natl Acad Sci U S A 2013, 110:E4858-4866.

116. Gerstberger S, Hafner M, Tuschl T: A census of human RNA-binding proteins. Nat Rev Genet 2014, 15:829-845.

117. Watanabe H, Kuhn A, Fushiki M, Agata K, Ozbek S, Fujisawa T, Holstein TW: Sequential actions of beta-catenin and Bmp pattern the oral nerve net in Nematostella vectensis. Nat Commun 2014, 5:5536.

118. Royo JL, Maeso I, Irimia M, Gao F, Peter IS, Lopes CS, D'Aniello S, Casares F, Davidson EH, Garcia-Fernández J, Gómez-Skarmeta JL: Transphyletic conservation of developmental regulatory state in animal evolution. Proc Natl Acad Sci USA 2011, 108:14186-14191.

119. Gabut M, Samavarchi-Tehrani P, Wang X, Slobodeniuc V, O'Hanlon D, Sung HK, Alvarez M, Talukder S, Pan Q, Mazzoni EO, et al: An Alternative Splicing Switch Regulates Embryonic Stem Cell Pluripotency and Reprogramming. Cell 2011, 147:132-146.

120. Kiselev Y, Eriksen TE, Forsdahl S, Nguyen LH, Mikkola I: $\mathbf{3 T 3}$ cell lines stably expressing Pax6 or Pax6(5a)--a new tool used for identification of common and isoform specific target genes. PLoS One 2012, 7:e31915.

121. Weise A, Bruser K, Elfert S, Wallmen B, Wittel Y, Wöhrle S, Hecht A: Alternative splicing of Tcf7/2 transcripts generates protein variants with differential promoter-binding and transcriptional activation properties at Wnt/beta-catenin targets. Nucleic Acids Res 2010, 38:1964-1981.

122. Laurent B, Ruitu L, Murn J, Hempel K, Ferrao R, Xiang Y, Liu S, Garcia BA, Wu H, Wu $F$, et al: A specific LSD1/KDM1A isoform regulates neuronal differentiation through H3K9 demethylation. Mol Cell 2015, 57:957-970.

123. Wang J, Telese F, Tan Y, Li W, Jin C, He X, Basnet H, Ma Q, Merkurjev D, Zhu X, et al: LSD1n is an H4K20 demethylase regulating memory formation via transcriptional elongation control. Nat Neurosci 2015, 18:1256-1264.

124. Kaitsuka T, Tomizawa K, Matsushita M: Transformation of eEF1Bdelta into heatshock response transcription factor by alternative splicing. EMBO Rep 2011, 12:673-681.

125. Raj B, O'Hanlon D, Vessey JP, Pan Q, Ray D, Buckley NJ, Miller FD, Blencowe BJ: Cross-Regulation between an Alternative Splicing Activator and a Transcription Repressor Controls Neurogenesis. Mol Cell 2011, 43:843-850.

126. Du S, Lawrence EJ, Strzelecki D, Rajput P, Xia SJ, Gottesman DM, Barr FG: Coexpression of alternatively spliced forms of PAX3, PAX7, PAX3-FKHR and PAX7-FKHR with distinct DNA binding and transactivation properties in rhabdomyosarcoma. Int J Cancer 2005, 115:85-92.

127. Huang H, Rastegar M, Bodner C, Goh SL, Rambaldi I, Featherstone M: MEIS C termini harbor transcriptional activation domains that respond to cell signaling. J Biol Chem 2005, 280:10119-10127.

128. Gueroussov S, Gonatopoulos-Pournatzis T, Irimia M, Raj B, Lin ZY, Gingras AC, Blencowe BJ: An alternative splicing event amplifies evolutionary differences between vertebrates. Science 2015, 349:868-873.

129. Dogan ES, Liu C: Three-dimensional chromatin packing and positioning of plant genomes. Nat Plants 2018, 4:521-529.

130. Dong P, Tu X, Chu PY, Lu P, Zhu N, Grierson D, Du B, Li P, Zhong S: 3D Chromatin Architecture of Large Plant Genomes Determined by Local A/B Compartments. Mol Plant 2017, 10:1497-1509. 
131. Wang M, Tu L, Lin M, Lin Z, Wang P, Yang Q, Ye Z, Shen C, Li J, Zhang L, et al: Asymmetric subgenome selection and cis-regulatory divergence during cotton domestication. Nat Genet 2017, 49:579-587.

132. Wang $M$, Wang $P$, Lin M, Ye Z, Li G, Tu L, Shen C, Li J, Yang Q, Zhang X: Evolutionary dynamics of 3D genome architecture following polyploidization in cotton. Nat Plants 2018, 4:90-97.

133. Oka R, Zicola J, Weber B, Anderson SN, Hodgman C, Gent JI, Wesselink JJ, Springer NM, Hoefsloot HCJ, Turck F, Stam M: Genome-wide mapping of transcriptional enhancer candidates using DNA and chromatin features in maize. Genome Biol 2017, 18:137.

134. Clark RM, Wagler TN, Quijada P, Doebley J: A distant upstream enhancer at the maize domestication gene tb1 has pleiotropic effects on plant and inflorescent architecture. Nat Genet 2006, 38:594-597.

135. Stam M, Belele C, Ramakrishna W, Dorweiler JE, Bennetzen JL, Chandler VL: The regulatory regions required for $B^{\prime}$ paramutation and expression are located far upstream of the maize b1 transcribed sequences. Genetics 2002, 162:917-930.

136. de Mendoza A, Bonnet A, Vargas-Landin DB, Ji N, Li H, Yang F, Li L, Hori K, Pflueger J, Buckberry $S$, et al: Recurrent acquisition of cytosine methyltransferases into eukaryotic retrotransposons. Nat Commun 2018, 9:1341.

137. Brate J, Neumann RS, Fromm B, Haraldsen AAB, Tarver JE, Suga H, Donoghue PCJ, Peterson KJ, Ruiz-Trillo I, Grini PE, Shalchian-Tabrizi K: Unicellular Origin of the Animal MicroRNA Machinery. Curr Biol 2018, 28:3288-3295 e3285.

138. Irimia M, Weatheritt RJ, Ellis J, Parikshak NN, Gonatopoulos-Pournatzis T, Babor M, Quesnel-Vallières M, Tapial J, Raj B, O'Hanlon D, et al: A highly conserved program of neuronal microexons is misregulated in autistic brains. Cell 2014, 159:1511-1523.

139. Li YI, Sanchez-Pulido L, Haerty W, Ponting CP: RBFOX and PTBP1 proteins regulate the alternative splicing of micro-exons in human brain transcripts. Genome Res 2015, 25:1-13.

140. Raj B, Irimia M, Braunschweig U, Sterne-Weiler T, O'Hanlon D, Yuan-Lin Z, Chen IG, Easton L, Ule J, Gingras AC, et al: Global regulatory mechanism underlying the activation of an exon network required for neurogenesis. Mol Cell 2014, 56:90103.

141. Torres-Méndez A, Bonnal S, Marquez Y, Roth J, Iglesias M, Permanyer J, Almudí I, O'Hanlon D, Guitart T, Soller $M$, et al: The evolutionary origin of neural microexons. Nature Ecol Evol 2019, In press.

142. Tessier LH, Keller M, Chan RL, Fournier R, Weil JH, Imbault P: Short leader sequences may be transferred from small RNAs to pre-mature mRNAs by trans-splicing in Euglena. EMBO $J$ 1991, 10:2621-2625.

143. Hastings KE: SL trans-splicing: easy come or easy go? Trends Genet 2005, 21:240-247.

144. Blumenthal $\mathrm{T}$ : Trans-splicing and polycistronic transcription in Caenohabditis elegans. Trends Genet 1995, 11:132-136.

145. Ganot P, Kallesoe T, Reinhardt R, Chourrout D, Thompson EM: Spliced-Leader RNA trans Splicing in a Chordate, Oikopleura dioica, with a Compact Genome. Mol Cell Biol 2004, 24:7795-7805.

146. Blumenthal T: Operons in eukaryotes. Brief Funct Genomic Proteomic 2004, 3:199211.

147. Warzecha CC, Shen S, Xing Y, Carstens RP: The epithelial splicing factors ESRP1 and ESRP2 positively and negatively regulate diverse types of alternative splicing events. RNA Biol 2009, 6:546-562.

148. Warzecha CC, Jiang P, Amirikian K, Dittmar KA, Lu H, Shen S, Guo W, Xing Y, Carstens RP: An ESRP-regulated splicing programme is abrogated during the epithelial-mesenchymal transition. EMBO J 2010, 29:3286-3300. 
149. Dittmar KA, Jiang P, Park JW, Amirikian K, Wan J, Shen S, Xing Y, Carstens RP: Genome-wide determination of a broad ESRP-regulated posttranscriptional network by high-throughput sequencing. Mol Cell Biol 2012, 32:1468-1482.

150. Miki T, Bottaro DP, Fleming TP, Smith CL, Burgess WH, Chan AM, Aaronson SA: Determination of ligand-binding specificity by alternative splicing: two distinct growth factor receptors encoded by a single gene. Proc Natl Acad Sci U S A 1992, 89:246-250.

151. Turner N, Grose R: Fibroblast growth factor signalling: from development to cancer. Nat Rev Cancer 2010, 10:116-129.

152. De Moerlooze L, Spencer-Dene B, Revest JM, Hajihosseini M, Rosewell I, Dickson C: An important role for the IIIb isoform of fibroblast growth factor receptor 2 (FGFR2) in mesenchymal-epithelial signalling during mouse organogenesis. Development 2000, 127:483-492.

153. Burguera D, Marquez Y, Racioppi C, Permanyer J, Torres-M?ndez A, Esposito R, Albuixech-Crespo B, Fanlo L, D'Agostino Y, Gohr A, et al: Evolutionary recruitment of flexible Esrp-dependent splicing programs into diverse embryonic morphogenetic processes. Nat Commun 2017, 8:1799.

154. Brunet $T$, Bouclet A, Ahmadi P, Mitrossilis D, Driquez B, Brunet AC, Henry L, Serman $F$, Bealle G, Menager $C$, et al: Evolutionary conservation of early mesoderm specification by mechanotransduction in Bilateria. Nat Commun 2013, 4:2821.

155. Pukhlyakova E, Aman AJ, Elsayad K, Technau U: beta-Catenin-dependent mechanotransduction dates back to the common ancestor of Cnidaria and Bilateria. Proc Natl Acad Sci U S A 2018, 115:6231-6236.

156. Almuedo-Castillo $M$, Salo $E$, Adell $T$ : Dishevelled is essential for neural connectivity and planar cell polarity in planarians. Proc Natl Acad Sci U S A 2011, 108:2813-2818.

157. Klein TJ, Mlodzik M: A conserved signaling cassette regulates hair patterning from Drosophila to man. Proc Natl Acad Sci U S A 2004, 101:9173-9174.

158. Gao B: Wnt regulation of planar cell polarity (PCP). Curr Top Dev Biol 2012, 101:263-295.

159. Devenport D: The cell biology of planar cell polarity. J Cell Biol 2014, 207:171179.

160. Momose $T$, Kraus $\mathrm{Y}$, Houliston $\mathrm{E}$ : A conserved function for Strabismus in establishing planar cell polarity in the ciliated ectoderm during cnidarian larval development. Development 2012, 139:4374-4382.

161. Schenkelaars Q, Fierro-Constain L, Renard E, Borchiellini C: Retracing the path of planar cell polarity. BMC Evol Biol 2016, 16:69.

162. Schenkelaars Q, Quintero O, Hall C, Fierro-Constain L, Renard E, Borchiellini C, Hill $A L$ : ROCK inhibition abolishes the establishment of the aquiferous system in Ephydatia muelleri (Porifera, Demospongiae). Dev Biol 2016, 412:298-310.

163. de Mendoza A, Sebe-Pedros A, Ruiz-Trillo I: The evolution of the GPCR signaling system in eukaryotes: modularity, conservation, and the transition to metazoan multicellularity. Genome Biol Evol 2014, 6:606-619.

164. Finn RD, Bateman A, Clements J, Coggill P, Eberhardt RY, Eddy SR, Heger A, Hetherington K, Holm L, Mistry J, et al: Pfam: the protein families database. Nucleic Acids Res 2014, 42:D222-230.

165. Schippers KJ, Nichols SA: Evidence of Signaling and Adhesion Roles for betaCatenin in the Sponge Ephydatia muelleri. Mol Biol Evol 2018, 35:1407-1421.

166. Windsor Reid PJ, Matveev E, McClymont A, Posfai D, Hill AL, Leys SP: Wnt signaling and polarity in freshwater sponges. BMC Evol Biol 2018, 18:12.

167. Suga H, Chen Z, de Mendoza A, Sebe-Pedros A, Brown MW, Kramer E, Carr M, Kerner P, Vervoort M, Sanchez-Pons N, et al: The Capsaspora genome reveals a complex unicellular prehistory of animals. Nat Commun 2013, 4:2325. 
168. Modrek B, Lee CJ: Alternative splicing in the human, mouse and rat genomes is associated with an increased frequency of exon creation and/or loss. Nat Genet 2003, 34:177-180.

169. Kopelman NM, Lancet D, Yanai I: Alternative splicing and gene duplication are inversely correlated evolutionary mechanisms. Nat Genet 2005, 37:588-589.

170. Roux J, Robinson-Rechavi M: Age-dependent gain of alternative splice forms and biased duplication explain the relation between splicing and duplication. Genome Res 2011, 21:357-363.

171. Irimia M, Maeso I, Gunning PW, Garcia-Fernandez J, Roy SW: Internal and external paralogy in the evolution of Tropomyosin genes in metazoans. Mol Biol Evol 2010, 27:1504-1517.

172. D'Aniello S, Irimia M, Maeso I, Pascual-Anaya J, Jiménez-Delgado S, Bertrand S, Garcia-Fernàndez J: Gene expansion and retention leads to a diverse tyrosine kinase superfamily in amphioxus. Mol Biol Evol 2008, 25:1841-1854.

173. Emerson RO, Thomas JH: Gypsy and the birth of the SCAN domain. J Virol 2011, 85:12043-12052. 